\title{
A Survey of Digital Health Interventions for Children with Cancer
}

\author{
Carmen Chai Wang Er ${ }^{1}$, Lau Bee Theng ${ }^{2}$, Abdullah Al Mahmud ${ }^{3}$, \\ Mark Tee Kit Tsun ${ }^{4}$ \\ ${ }^{1,2,4}$ Swinburne University of Technology - Sarawak Campus, Kuching, Sarawak, Malaysia \\ \{cchai,blau,mtktsun\}@swinburne.edu.my \\ ${ }^{3}$ Swinburne University of Technology, Melbourne, Victoria, Australia \\ aalmahmud@swin.edu.au
}

\begin{abstract}
Childhood cancer is the most common cause of death by illness in children globally. Fortunately, the survival rate of this deadly disease can be as high as $80 \%$ in high-income countries with cancer treatment. However, cancer treatments can result in large symptom burdens for children and adolescents. This, and many other factors can result in treatment non-adherence in cancer patients, which will strongly affect their survival rate. Therefore, it is important for interventions to be conducted in order to make the cancer experience more bearable. This survey reviews eleven existing game-based digital health interventions including Re-Mission and Ben's Game, and lists the various aims of these interventions, such as empowerment to fight cancer and symptom management. The game mechanics of these interventions are also identified and the ways these mechanics contribute to the aims of these interventions are analyzed. Finally, limitations of existing interventions are discussed and suggestions for future works are given.
\end{abstract}

Keywords: Childhood Cancer, Serious Game, Digital Health Intervention, Game Mechanics;

\section{Introduction}

Cancers that occur before the child is 15 years of age are referred to as childhood cancer. As this form of cancer occurs rarely, only $1.4 \%$ of all cancers worldwide comprises of childhood cancer [1], with an estimate of 163,000 new cases yearly [2]. For this article, the target group of children with cancer includes both children and adolescents aged 18 years and below.

This article aims to identify and analyze the ways existing game-based digital health interventions and their game mechanics that can help children with cancer. Although similar reviews [3], [4] have been done, they do not fit the aim of this review paper. The first review [3] focuses on various forms of digital interventions for adolescents and young adults with cancer, of which the majority are websites. The second review [4] touches on digital games in cancer management. However, it is an unsystematic review article with a broad focus, including educational tools for health care professionals. Neither of these reviews has discussed the game mechanic aspects of existing digital health interventions for childhood cancer patients.

The survival rate of cancer is high with proper cancer treatment such as surgery, chemotherapy and radiotherapy. However, chemotherapy and radiotherapy can cause significant symptom burdens for children and adolescents. These symptoms or treatment side effects often begin during the treatment period but may continue to occur even after completion of treatment [5], [6]. Common cancer treatment side effects and symptoms 
that cause problems for children who are going through cancer treatment include pain, fatigue, nausea, mucositis, and malnutrition. The prevalence and severity of many treatment side effects and symptoms will lessen over time [7], [8].

Many childhood cancer patients have been hospitalized for a long time during the cancer treatment process which causes them a large amount of stress and may affect these young patients socially, physically, emotionally and psychologically [9].

Additionally, the shocking discovery of having a possibly deadly disease by the young patients often results in a wide range of emotions, including worry, depression and anxiety [10], [11]. Experiencing difficulties in performing daily tasks and being unable to socialize like normal due to the disease, its symptoms and the treatment side effects can result in frustration, anger, and feelings of uncertainty in their situation, and this can further lead to more social isolation [12].

Even though cancer treatment is essential for surviving cancer, there are many factors, which may lead to treatment refusal, treatment non-adherence or even treatment abandonment in cancer patients. The occurrence of treatment non-adherence is not unique to childhood cancer patients, in fact, treatment non-adherence is an ongoing problem for other medical forms of treatment as well [13].

There are also some patient-centered factors that may result in treatment nonadherence. Adolescent patients have been reported to have more difficulties adhering to treatment due to being immature. They do not consider the future consequences of their actions and may resort to risky behaviors such as not following the treatment. [14], [15]. Children can also be prone to treatment non-adherence, due to lack of understanding of the treatment and also believing that they could stop treatment without consequences [16]. Other patient-centered factors include forgetfulness, lack of motivation and lack of support to keep up with treatment [17].

Even though going through cancer is a stressful experience, many childhood cancer patients have survived the ordeal and gone on to live a good and normal life [18]-[21]. Therefore, it is essential to know how to cope with cancer to improve survivability, reduce symptom severity and increase treatment effectiveness. Some ways of coping with cancer include getting more informed about cancer, cancer treatment and treatment side effects [22], [23], having emotional and social support [22], [24], having a positive view on the experience [19], getting enough physical activity [25] and play [26], [27], getting enough nutrition [5], [28] and fluids [29], [30], practicing good hygiene [8], [31], and sharing thoughts and worries about their situation [11], [32].

Various studies interventions for cancer patients have been conducted to address their various needs. Examples of such interventions include psychosocial interventions which aim to increase the cancer patients' psychosocial status [32], [33] to help them cope more positively with cancer, and physical activity interventions [34]-[37] which aim to increase the physical activity and exercise done by cancer patients to boost self-efficacy to exercise and reduce feelings of fatigue.

However, common interventions have multiple shortcomings compared to digital interventions. These include being difficult to reproduce the same intervention for different participants, requiring more workforce and person-hours to conduct the intervention for each participant, the lack of portability, and the lack of interesting elements. According to Phillips \& Davis [32], compared to more conventional forms of interventions, digital health interventions (DHI) are regarded to be more appealing to the younger age group of adolescents and young adults due to their high interest in electronics and technology.

DHIs are potentially safe, scalable, effective and cost-effective forms of interventions. These interventions can come in the form of websites, computer programs, mobile applications, and serious games, and are used to improve the health and health care of the participants. [38]

Additionally, DHIs which involve interactive technology have a high appeal towards the younger generation such as adolescents and young adults as they are comfortable with 
using electronics and new technology [32]. It is even suitable for young children, as they are found to be adept at using interactive technology devices on their own [39].

Due to the limited number of papers on DHIs with game elements for children with cancer, DHI for adolescents and adult patients, have been included for consideration in this survey paper as well.

\section{Methodology}

In order to obtain the interventions for the review, interventions were searched for in various ways as depicted in Table 1 below. A total of 11 game-based DHIs were selected for analysis. Some interventions have multiple articles; each article referenced in this review is included as it contributes a different aspect of the game mechanics or intervention process.

Table 1. Search methods used to find suitable interventions for review.

\begin{tabular}{|c|c|c|c|c|}
\hline $\begin{array}{l}\text { Search terms } \\
\text { (keywords) }\end{array}$ & $\begin{array}{l}\text { Database/Search } \\
\text { engine used }\end{array}$ & $\begin{array}{l}\text { No. of } \\
\text { results } \\
\text { yielded }\end{array}$ & \begin{tabular}{|l|} 
No. of \\
interventions \\
after inclusion \\
criteria applied \\
\end{tabular} & Interventions \\
\hline $\begin{array}{l}\text { ("serious game" } \\
\text { AND "cancer") } \\
\text { patients }\end{array}$ & \multirow{2}{*}{$\begin{array}{l}\text { ScienceDirect (Filtered } \\
\text { to "Journal Articles" } \\
\text { only) }\end{array}$} & 37 & 4 & $\begin{array}{l}\text { 1) Pain Buddy } \\
\text { 2) INTERACCT } \\
\text { 3) iManageCancer - } \\
\text { adult serious game } \\
\text { 4) iManageCancer - } \\
\text { children serious game }\end{array}$ \\
\hline $\begin{array}{l}\text { ("gamification" } \\
\text { AND "cancer") } \\
\text { patients }\end{array}$ & & 54 & $\begin{array}{r}2 \\
(2 \text { found in } \\
\text { previous search })\end{array}$ & $\begin{array}{l}\text { 1) iManageCancer - } \\
\text { adult serious game } \\
\text { 2) iManageCancer - } \\
\text { children serious game }\end{array}$ \\
\hline $\begin{array}{l}\text { "serious game" } \\
\text { AND "cancer" } \\
\text { patients }\end{array}$ & \multirow{2}{*}{$\begin{array}{l}\text { ProQuest (filtered to } \\
\text { "Dissertations \& Theses" } \\
\text { OR "Scholarly } \\
\text { Journals") }\end{array}$} & 243 & $\begin{array}{r}3 \\
\text { (3 found in } \\
\text { previous search })\end{array}$ & $\begin{array}{l}\text { 1) Pain Buddy } \\
\text { 2) iManageCancer - } \\
\text { adult serious game } \\
\text { 3) iManageCancer - } \\
\text { children serious game }\end{array}$ \\
\hline $\begin{array}{l}\text { "gamification" } \\
\text { AND "cancer" } \\
\text { patients }\end{array}$ & & 446 & 0 & N/A \\
\hline games for cancer & Google generated list & 5 & 2 & $\begin{array}{l}\text { 1) Re-Mission } \\
\text { 2) Ben's Game }\end{array}$ \\
\hline $\begin{array}{l}\text { digital games for } \\
\text { children with } \\
\text { cancer }\end{array}$ & \multirow[t]{2}{*}{ Google } & N/A & $\begin{array}{r}4 \\
(2 \text { found in } \\
\text { previous search })\end{array}$ & $\begin{array}{l}\text { 1) Empower Stars! } \\
\text { 2) iManageCancer - } \\
\text { adult serious game } \\
\text { 3) iManageCancer - } \\
\text { children serious game } \\
\text { 4) Cytarius }\end{array}$ \\
\hline \multirow[t]{2}{*}{$\begin{array}{l}\text { "serious game" } \\
\text { AND "cancer" } \\
\text { patients }\end{array}$} & & N/A & $\begin{array}{r}2 \\
\text { (1 found in } \\
\text { previous search })\end{array}$ & $\begin{array}{l}\text { 1) INTERACCT } \\
\text { 2) ILOVEBREAST }\end{array}$ \\
\hline & $\begin{array}{l}\text { Found the name of DHI } \\
\text { from online web articles } \\
\text { while performing above } \\
\text { searches on Google }\end{array}$ & N/A & $\begin{array}{r}3 \\
(1 \text { found in } \\
\text { previous search })\end{array}$ & $\begin{array}{l}\text { 1) Pain Squad } \\
\text { 2) Re-Mission } \\
\text { 3) Re-Mission } 2\end{array}$ \\
\hline \multicolumn{3}{|c|}{ Total interventions after removing the duplicates } & 11 & \\
\hline
\end{tabular}


Interventions that do not meet all the inclusion criteria set are excluded. The following list shows the inclusion criteria:

- Uses gamification or is a serious game

- Targets cancer patients of any age

- Game mechanics are discussed in the publications

- Is published from 01-01-2000 onwards

- Is written in English

The interventions included in this review in alphabetical order are: Ben's Game, Cytarius, Empower Stars!, ILOVEBREAST, iManageCancer (serious game for adult), iManageCancer (serious game for children), INTERACCT, Pain Buddy, Pain Squad, ReMission, and Re-Mission 2. It should also be noted that even though some interventions included have no reports on the effectiveness of the intervention through research trials with cancer patient participants, these have still been included as the primary focus of this review is on game aims and game mechanics.

In order to analyze the interventions selected, articles of each intervention are read thoroughly to identify common themes based on the categories of the intervention's aim (also referred to as "game aim") and game mechanics that support the design of these interventions to achieve the game aims. Using the identified themes, game aim codes and game mechanic codes were determined. Finally, an analysis of how the different game mechanics are used to achieve each game aim is done.

\section{Digital health interventions for cancer patients}

This section reviews eleven DHIs for cancer patients: two mobile applications with game elements and nine serious games.

Each intervention is described briefly and an analysis of how the game mechanics included in the design of the game is able to help with achieving the identified game aims is performed.

\subsection{Ben's Game}

Ben's Game [40], [41] is a computer action shooter game. Ben, a young leukemia patient, used his wish from the Make-A-Wish Foundation of America to create a game for children with cancer to help them to fight cancer.

The main aim of the game is to provide players with empowerment to fight cancer. To achieve this aim, the game contains game mechanics for fighting enemies. In this game, players take the role of a child on a hoverboard who has been shrunk down to fight enemies in the body. The enemies of the game are mutated cancer cells and seven boss monsters that are the embodiment of common cancer symptoms, namely, colds, rashes, vomiting, fever, chicken pox, bleeding, and hair loss. The hero of this game has three statuses to fight the enemies with, which are health from the hospital, ammo from the pharmacy, and attitude from home. Additionally, players cannot be killed in the game to encourage players to not give up on their fight with cancer.

The second objective of the game is to provide education on cancer and cancer related information. The game shows seven common symptoms of cancer the form of enemy monsters and the use of treatment to fight them. Players can casually learn about the common symptoms of cancer and treatment side effects. In addition, by using medicine from the pharmacy as ammo to fight cancer cells and these enemies, players are taught that taking medication can help manage cancer and these common symptoms.

The game also utilizes the game mechanic, virtual rewards. Players can collect shields once they have completed a game level by killing all the cancer cells and the symptom based monster. The shield obtained will symbolize protection from that 
symptom. Virtual rewards are often used to encourage continuous play. Players of Ben's Game would continue playing in order to collect all seven shields available.

This game does not have any formal intervention evaluation but is well received among their players, doctors and game designers. [42]

\subsection{Cytarius}

Cytarius [43] is a computer strategy game created for children and adolescents with cancer. One of the game's main aim is education on cancer and cancer related information. In this case, the game demonstrates through gameplay how cancer treatments work. One of the game mechanics of the game is fighting enemies. In this game, players take the role of a strategic commander who is tasked with controlling the enemies' activities to protect two planets. Players are able to deploy weapons that are based on real cancer treatments to fight the enemies, which are based on cancer cells. In this way, players can casually learn about cancer treatment. The increase in understanding on cancer also promotes discussion on the disease among young cancer patients, their parents and the medical staff. As the game includes fighting enemies, another aim of the game would be the empowerment of patients to fight cancer.

The results of the intervention evaluation conducted with 23 children and adolescents with cancer showed that the game was positively rated by the participants. However, the effects of the game in terms of patients' health and attitudes towards cancer and its treatment were not evaluated. Interviews conducted with ten parents of children or adolescents with cancer, and five health care providers showed that both parties considered the game to have high educational potential for teaching children about cancer.

\subsection{Empower Stars!}

Empower Stars! [44] is a mobile puzzle exergame playable on the tablet device. It is played with special printed 3D handlebars attached to the tablet device, and is made for children with cancer who are often sedentary during treatment. Exergames are video games that require physical movement to play and are considered a type of exercise [45]. In this game, players take the role of a space explorer and are asked to terraform a barren planet that has been overrun by the enemy, Cercer crabs. The Cercer crabs are depictions of cancer in the game. Players can save the planet by exercising and solving puzzles.

This game has the primary objective of encouraging good health habits in children with cancer; in this case it encourages physical activity and healthy eating. Empower Stars! contains 30 minutes of gameplay time, of which 20 minutes involves physical exercise. This is achieved through the physical movement detection game mechanic. Throughout the game, players will be asked to perform 30 seconds long exercise by swinging or moving the tablet. The game was designed so that only a little movement in the right direction will trigger the star reward system for exercising. This is in consideration of players that may not feel well enough to move vigorously. However, the game will also encourage more vigorous movements as there are more star rewards provided to those that exercised vigorously during these sessions.

The reward system is related to the game mechanic, virtual reward where in-game rewards are provided to players for performing game tasks. Additionally, there is a minigame game mechanic to educate children about healthy and unhealthy foods to encourage healthy eating.

Another objective of the game is to provide players with empowerment to fight cancer. In this game, there is also the fighting enemies game mechanic. However, rather than physical combat, players are able to defeat the Cercer crabs by terraforming a barren planet through solving puzzles and exercising. Players are also not able to die in this game during their quest to restore the planet to full health.

The third objective of Empower Stars! is to provide education on cancer and cancerrelated information. Throughout the game, messages are displayed about cancer and 
pag. 76

treatment-related facts so that players may read them. These messages address answers to common questions such as "What is cancer", "What is radiotherapy?", "What is chemotherapy?", "What are cancer treatment side effects?", and "How can I get stronger and healthier?".

The one-day intervention was conducted with 10 children with cancer ranging from age 7-14 years old to test the usability, engagement and enjoyment of the game. Overall, there is wide acceptance and enthusiasm for including exercise along with fighting cancer as part of the game by children participants. Parents and health care providers were also in agreement that the inclusion of physical activity and themes of empowerment when playing the game will be beneficial to children with cancer.

\subsection{ILOVEBREAST}

The game ILOVEBREAST [46], is a mobile life simulation game developed for patients with metastatic breast cancer who plan to go through cytotoxic chemotherapy.

The main aims of the game are the empowerment to fight cancer, provide education on cancer, allow symptom management, and encourage good health habits in participants. These aims are achieved through various game mechanics.

The first game mechanic happens at the beginning of the game, which is the custom avatar or character game mechanic. The avatar generated is based on the patient's health information related to the chemotherapy treatment, and includes their general medical condition and chemotherapeutic drugs to be taken. This customization will affect the game in terms of side effects management and medication taken for the avatar. Players can also customize the appearance of their avatars when they obtain more hats and gloves for their avatar to wear.

The next game mechanic is role-modelling. The avatars created live in a virtual town and players are given the goal to help manage their avatar's breast cancer by performing daily tasks in the town. Players can receive prescribed medications, cook food appropriate for their health, and exercise. As players take care of their avatars, they will be shown that their avatars are leading healthier lives. This sends a message to the player that self-care during cancer treatment is important.

Another game mechanic used to achieve the above game aims is the quests/challenges system game mechanic. Players are given extra quests to complete to help them minimize the side effects of chemotherapy and often include good health habits such as exercising, going outside for a walk, chatting with a friend, cooking a healthy meal, and taking their medications at the right time.

This leads to the fourth game mechanic, which is the virtual rewards game mechanic. As quests are completed, heart coins are rewarded to the player. The more heart coins collected by the player, the greater the improvement to their avatar's health. These coins can also be used to buy new hats, gloves and food ingredients for their character. This will motivate players to complete quests in the game.

One more aim of the game is to improve treatment adherence of the players. The game contains an alarm system mechanic, which will remind the players to give their avatars their medication on time. Coupled with the quest that provides rewards for the timely intake of medication, players are reminded and encouraged to adhere to their own treatment regimes.

By managing the life of their avatar counterpart within the game, patients learn more about cancer, become aware of the importance of cancer treatment, discover the various ways of symptom management, and realize the importance of healthy habits.

The intervention of this game was conducted with 76 breast cancer patients of mean age 50.7 years old (SD 7.0), who were on cytotoxic chemotherapy. 40 of these participants were placed in the conventional education group, while the other 36 were placed in the mobile game group. Participants were asked to study materials or play the game for 3-week intervention period. Results showed that the mobile game group were better at adhering to their chemotherapy medicine. Additionally, those who played 
ILOVEBREAST had also reported less chemotherapy-related side effects, and also exhibited better quality of life during chemotherapy than the control group.

\section{5 iManageCancer}

iManageCancer [47] is a personal health record system and self-management platform for cancer patients. Two serious games for cancer patients, one for adults, and one for children, have been developed to be integrated in this platform [48] with the objective to help them manage the negative impact of cancer on their psychological wellbeing and to help motivate them to become more social and stay positive.

The first iManageCancer game targets adults with cancer, and is a mobile town management game. Adults with cancer often find it confusing and frustrating to balance their lifestyle after the diagnosis of the disease. The game aims to provide empowerment to fight cancer in terms of teaching players how to manage a more balanced and healthier lifestyle while managing their disease. In this game, the player takes the role of the mayor of a town who is asked to solve the problems of the town members. The game mechanic, custom avatar or character will allow players to customize the appearance of their avatar and city. This helps to establish a bond with players to their character. The next game mechanic would be role-modelling. As players try to solve the problems of the town members, they are able to see the effects of their decisions, whether good or bad, on the town and its members. This shows the players the importance of maintaining a balanced and healthy lifestyle.

The game also features a quests/challenges system game mechanic. Every level of the game, players must help a town member to get their wellbeing to $100 \%$. Players are also given other quests to encourage the development of the town. These quests give players a goal to work towards and encourage gameplay.

Related aims also include the aim to encourage healthy habits and to discourage unhealthy ones, and also the aim for symptom management. In addition to learning the effects of certain health habits while solving the issues of the town members, a mini-game game mechanic in the form of a quiz game is provided to pose a large number of lifestyle and health related trivia questions to players. Players can repeat this mini-game as often as they want to learn more about good lifestyle choices.

A social game-mechanic is also added to encourage players to socialize with other players of the game. Players can create their own profile and view the basic profile of others to send them friend requests. Friends in this game are able to help one another by occupying a friend's town to provide an additional, positive, passive effect for their game. The social profiles viewable in the game do not contain any of the players' medical data and only displays the players' avatars and email address contacts. Players are also encouraged to perform physical activities as the game has a virtual reward mechanic, which awards players with virtual coins to spend in the game for the physical activities logged on the iManageCancer platform.

Intervention results [49] from a large-scale pilot of 135 adult cancer patients conducted over 6-10 weeks showed mixed evidence for the improvements of patient empowerment due to the effects of the treatment that induce psychological problems and stress, as well as the lack of time. However, mood, cancer resilience, and coping with cancer were shown to have improved among the participants.

The second iManageCancer game targets children and adolescents with cancer, and is a mobile action shooter game. The game's main aim is the empowerment of players to fight cancer. This is achieved through the fighting enemies game mechanic. In this game, players fly around in the human body searching for cancer cells to destroy. Players are given various types of weapons that are based on therapy tools against cancer to destroy their enemies. Being able to fight cancer back rather than passively receiving treatment will help direct the players' energy and feelings of frustration at their situation to beating cancer and getting better. The depiction of existing treatment as weapons in the game helps with the game's aim of educating about cancer and cancer treatment. 
The other main objective of the game is to encourage healthy habits. In this case, the focus is given to socializing, as children with cancer as often isolated during treatment. The social game mechanic encourages socializing with the players by allowing the friends and families of players to show their support towards the players' virtual fight against cancer. Support obtained in the game from friends and family members will improve the abilities of the players' weapons to fight cancer. Additionally, there is a multiplayer mode where multiple players can work together to take down a boss monster in the form of a very nasty special cancer cell. The virtual reward game mechanic also further encourages socializing of players as participating in the multiplayer boss fight will provide a virtual sticker reward for players' sticker albums.

Intervention results [49] obtained from a small-scale testing of the pilot game with 15 children with cancer showed that participants recognized the usefulness of the game and found it user friendly. However, many parents were concerned that the game objective of shooting down cancer cells might be too difficult for their children, which they believe could lead to additional stress for the young patients.

\subsection{INTERACCT}

INTERACCT (Integrating Entertainment and Reaction Assessment into Child Cancer Therapy) [50] is a mobile adventure exploration game that targets children and adolescents with cancer, namely patients who had gone through hematopoietic stem cell transplantation. In this game, players control a pet-based avatar and explore parts of an island to collect items and fight enemies.

One aim of this intervention is the empowerment to fight cancer, and is related to the game mechanic, fighting enemies. Although the enemies of this game are not depictions or representations of cancer, the medical expert on INTERACCT's development team pointed out that simply the act of being able to fight back is enough to provide emphasis to fighting cancer through cancer therapy and symptom management.

The second aim is for symptom management. To aid in achieving this aim, the game includes the game mechanic of symptom and health reporting. Players are asked daily to fill in a report form which asks about various health related aspects such as their fluid intake, stool consistency, appetite levels, and problems faced when taking fluids or passing stool. The content of this form depends on their current treatment and is assigned by their health care provider. The game aim of encouraging healthy habits is achieved through the mini-game game mechanic. Health care providers can assign these medicalpurposed mini-games for players to play based on their symptom and health report. Examples of the medical purposes of these mini-games are improving patients' fitness levels, encouraging fluid intake, and training the patients' ability to stay focused. [51]

Both the aim of symptom management, and the game mechanic of symptom and health reporting are related to the game aim of communication with health care providers. Health care providers can monitor their patient's status via the symptom and health reports, and can prescribe mini games to the patient to improve symptom management.

The game encourages long term game play through the use of the following game mechanics. The game has the custom avatar or character game mechanic where players can improve the skills of their pet avatar and choose which pet to use as their avatar. The virtual reward game mechanic is in the form of "research points". Players can obtain these "research points" from the daily reporting of their symptom and health status, and can use this virtual currency to upgrade their pets. The game also has the unlockables mechanic. As players make progress in the game, they will be able to unlock, collect and use new pets to explore the island. Finally, the random level generator game mechanic is used to create random instances of the game level. This results in a different game scenario each time the player explores the island so that players will not find the game to be boring and repetitive.

The evaluation of this serious game intervention has yet to be conducted. 


\subsection{Pain Buddy}

Pain Buddy [52] is a mobile pain diary application made for children and adolescents with cancer. This application features a Pain Buddy character, which will provide support to the users during their pain management journey.

The main aim of the application is symptom management. Through the game mechanic of symptom and health reporting, users can report which part of their body is in pain and the levels of pain. This report is done at least once a day, and the data is sent to a central server for storage and monitoring. Whenever any of the reports exceed the predetermined thresholds, an alert is sent to the health care providers of the child as an intervention may be warranted.

This leads to the next aim of the application, which is to encourage communication with health care providers. Through the alert from the server, health care providers can be made aware in real time about the problem. This will lead to faster treatment recommendations for the patients' pain and other symptom managements before the situation further escalates. Additionally, through the health care provider web portal, providers are able to view and monitor all their patients' data in real time.

The second aim of the application is education on cancer, in the form of teaching management techniques of the pain symptom. This aim is also connected to the earlier mentioned aim of symptom management. Through the game mechanic of role-modelling, the application demonstrates symptom management techniques via the Pain Buddy character via speech and animation. Along with the demonstration, the application also provides opportunities for users to rehearse pain management strategies that do not involve taking analgesics. Examples are: progressive muscle relaxation, guided imagery, mindfulness, distraction, and diaphragmatic breathing.

Game mechanics that promote the usage of the application include the custom avatar or character mechanic, and the virtual rewards mechanic. Users can customize the appearance of their Pain Buddy by dressing them up with items. Virtual rewards in the form of Pain Buddy "coins" are given when users engage with the application. These coins can be used to buy additional items to dress up their Pain Buddies with, change background appearance, change the design layout of the application and others.

The pilot study intervention conducted over a 10-day period with 12 children and adolescents with cancer ranging from age 8-18 found that participants enjoyed using the application and were motivated to report their symptoms. Many participants had also expressed that they would recommend this application to a friend undergoing cancer treatment. Mean number of pain diary entries completed by participants was 19.68 (SD 4.64, range 13-27), indicating that many participants were motivated to report more than once a day.

\subsection{Pain Squad}

Pain Squad [53] is a mobile pain diary application targeted towards adolescents with cancer. The application utilizes a game-like storyline where the users are recruited to hunt down pain and send it to jail by a special investigative force.

The primary aim of this application is for symptom management, namely the pain symptom. The game mechanic related to this is of symptom and health reporting. Twice a day, users are asked to complete a 20-question report on their pain symptom. The report logs the intensity, location and of the pain, in addition to the level of impact the pain has on their daily lives such as their mood, sleep, schoolwork and relationships. Users can also log their pain management strategies and the medications they use.

To encourage the use of the application, the game mechanic of virtual rewards was implemented. As the user logged more and more reports, they were rewarded by being able to move up the law enforcement team ranks, and were also given acknowledgement via pre-recorded video calls from fictitious officers. 
Usability testing conducted with 14 participants showed that they enjoyed using the app and its game-based nature and virtual reward system. Pain Squad achieved a mean of $88 \%$ compliance rate for pain reporting rate for 12 of participants in the 2 week testing period. The other two participants were not able to use their phone during the majority of the 2 week testing period and were not able to interact with the Pain Squad application.

\subsection{Re-Mission}

Re-Mission [54] is a computer action shooter game that has been developed for adolescents and young adult cancer patients. It is one of the first and most impactful serious games for cancer. In this game, players take the role of a nanobot named "Roxxi" who fights cancer inside the bodies of various virtual patients.

The first aim of Re-Mission is to provide players with the empowerment to fight cancer. This is supported by the game mechanic, fighting enemies. To beat the game, players have to shoot down cancer cells. In this game, death is not depicted either in the playable nanobot character or the virtual patients. Although players may fail a level, the nanobot simply powers down and the players can try the level again, encouraging players not to give up on their fight against cancer.

Using chemotherapy as the weapon to fight cancer cells leads to one of the main aims of the game, which is to improve treatment adherence among the players. By becoming aware of how chemotherapy works to fight cancer cells in their bodies, players will place more importance on adhering to their chemotherapy drug regime.

Additionally, the game also has three other related aims, which are symptom management, education on cancer, and encouraging good health habits. These aims are achieved through the use of the role modelling game mechanic. Besides shooting down cancer cells, players can also take care of the virtual patients by ensuring the patients use positive health care behaviours. Examples of such behaviours are gaining energy by eating food, fighting infection by taking antibiotics, combating oral mucositis by practicing good mouth care, preventing bowel perforations by using stool softeners, and reducing stress via relaxation techniques. Seeing the effects of using these self-care behaviours on the virtual patients' health can help players to realize the importance of these actions. Players will become educated on ways of managing their cancer and treatment related symptoms, and are encouraged to take better care of their own health.

The game was tested with 375 adolescents and young adults with cancer ranging from 13-39 years old. 197 of participants were placed in the intervention group and were assigned to play Re-Mission, while 178 were placed in the control group and were assigned to play a similar commercially available game. Both groups were asked to play the game for at least 1 hour per week for a period of 3 months. Results showed that the intervention group showed significant improvement in terms of treatment adherence. In addition, cancer-related self-efficiency and cancer-related knowledge were also increased in the intervention group. Also, no adverse effects of this form of intervention was reported and it is suggested to be safe for distribution to cancer patients.

\subsection{Re-Mission 2}

Re-Mission 2 [55] is a web-based collection of six free action based mini games. These games were made for adolescents and young adults with cancer after the success of the original, Re-Mission [56]. The aim of these mini-games are the empowerment to fight cancer, treatment adherence, and education on cancer. The game mechanic of these minigames is fighting enemies, as players are able to go inside their own body to shoot and destroy cancer cells with various kinds of weapons including chemotherapy, cancer drugs and their immune system. By being able to fight cancer, players became expose to the mechanics of their own treatment and became more diligent about taking their medication. They are also able to gain knowledge on how the treatment works from playing the game. 
In addition to the web-based version, a mobile version of one of the mini game named Re-Mission 2: Nanobot's Revenge [57] has also been developed. Being on the mobile platform increased the accessibility of the mini-game game to patients who are able to play on their mobile devices at anytime and anyplace such as clinics, waiting rooms, and even at home.

No evaluation has been conducted for this serious game intervention.

\subsection{Findings and discussions}

From the various publications reviewed, the game aim codes and game mechanic codes and aims are identified for each intervention, as well as the total number of interventions that contain the same game aim are shown in Table 2.

Table 2. Game aims of each DHI.

\begin{tabular}{|c|c|c|c|c|c|c|c|c|c|c|c|c|}
\hline Game aim code & 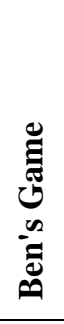 & 总 & 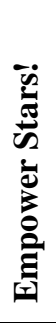 & 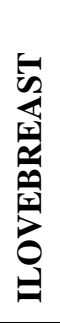 & 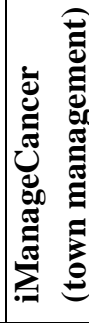 & 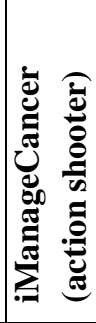 & 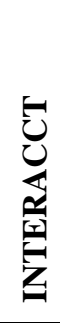 & 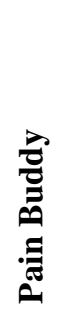 & 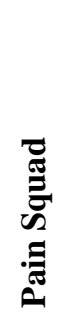 & 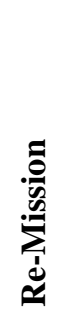 & 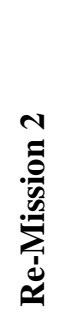 & 吾 \\
\hline $\begin{array}{l}\text { Empowerment } \\
\text { to fight cancer }\end{array}$ & 1 & 1 & 1 & 1 & 1 & 1 & 1 & & & 1 & 1 & 9 \\
\hline $\begin{array}{l}\text { Education on } \\
\text { cancer }\end{array}$ & 1 & 1 & 1 & 1 & & 1 & & 1 & & 1 & 1 & 8 \\
\hline $\begin{array}{l}\text { Encourage } \\
\text { healthy habits }\end{array}$ & & & 1 & 1 & 1 & 1 & 1 & & & 1 & & 6 \\
\hline $\begin{array}{l}\text { Symptom } \\
\text { management }\end{array}$ & & & & 1 & 1 & & 1 & 1 & 1 & 1 & & 6 \\
\hline $\begin{array}{l}\text { Treatment } \\
\text { adherence }\end{array}$ & & & & 1 & & & & & & 1 & 1 & 3 \\
\hline $\begin{array}{l}\text { Communication } \\
\text { with health care } \\
\text { providers }\end{array}$ & & & & & & & 1 & 1 & & & & 2 \\
\hline
\end{tabular}

Out of the 11 DHIs reviewed, many interventions have included the following game aims: empowerment to fight cancer (9), education on cancer (8), encourage healthy habits (6), and symptom management (6). These aims can be considered to address the most important and urgent needs for cancer patients and are able to improve the patients' selfefficacy in undergoing cancer treatment and taking care of their health in order to beat cancer. Game aims that are not as popular but still hold importance are treatment adherence (3), and communication with health care providers (2).

Achieving one game aim will often positively affect another. For example, by educating the patients about cancer symptoms and ways to manage it, symptom management is encouraged. Another example, by empowering patients to fight cancer, they will become more motivated to adhere to their treatment.

The game aims listed can be achieved in various ways. The first game aim is empowerment to fight cancer. Empowerment to fight cancer is achieved when patients are given a way to virtually fight back, regardless of whether it is against cancer or not. 6 out of 7 of the games (Ben's Game, Cytarius, Empower Stars!, iManageCancer (action shooter), Re-Mission and Re-Mission 2) that involved defeating enemies, depicted cancer cells in some variation as the enemies. Only INTERACCT had depicted the enemies as other things such as animals. The fight against the enemy does not have to be direct 
combat as well. Games like Cytarius had players strategically deploy treatment-based weapons to fight the enemies automatically, while Empower Stars! allowed players to defeat the enemies as a result of solving puzzles to save the planet. Other ways of empowerment is through knowledge on how to manage a healthy lifestyle during cancer treatment, as seen in the games for adults, ILOVEBREAST (life simulation) and iManageCancer (town management).

The second game aim of education on cancer is achieved by several means as well. The game mechanic of role-modelling allowed players to vicariously experience activities such as using cancer treatment to beat cancer, practicing symptom management, and practicing certain healthy habits to lead a healthier lifestyle. Even though all these happen in a virtual environment, players are able to learn from these experiences about the effects of certain actions. According to the Social Learning Theory, observational learning can occur even from symbolic models such as game characters [58]. Additionally, depictions of real life cancer related experiences in the game will also allow players to casually learn about it. An example would be the seven boss monsters based on real cancer and treatment related symptoms in Ben's Game. Through playing the game, players will become educated about these symptoms. The mini-game game mechanic is also utilized for educating players on cancer. A large variety of information such as food nutrition (Empower Stars!), healthy life style choices (iManageCancer (town management)), and symptom management (INTERACCT) can be the educational focus of these mini-games, where players will learn about them through playing. Another method of education on cancer would be to display cancer and cancer related facts to players throughout the game as done by Empower Stars!.

The third game aim is to encourage healthy habits. This is related to the game aim of education on cancer. Healthy habits can be learnt from the game mechanic of role modelling, where the avatar or characters in the game are seen to practice good healthy habits. The players can see through the game how these good healthy habits, or lack of it, affect the characters. Good habits can also be encouraged via the mini-game game mechanic where information on how to carry out such good health habits can be conveyed. For example, the food nutrition based game in Empower Stars! can help children to identify which foods are good for them and will encourage healthy eating. Additionally, games that are exergames such as Empower Stars! can encourage the healthy habit of exercising. The game has included the physical movement detection game mechanic and this helps to ensure that players physically move around while playing the game. The game mechanic of virtual rewards is also able to help in achieving this aim. In Empower Stars!, star rewards are given to players for carrying out physical activities. The more vigorously they exercised, the more star rewards were awarded. In ILOVEBREAST, heart coins were given to players for completion of tasks and goals set by the game through the game mechanic of quests/challenges, which consists of carrying out good healthy habits with the avatar. The social game mechanic can also be used to encourage cancer patients that are often isolated during treatment to socialize with others. Both games in the iManageCancer platform had incorporated this game mechanic. In the adults' game, socialization can be done by making friends with other players. In the children's game, socialization can be done by joining multiplayer content with other players. Friends and family members can also show support to these young patients in the game by sending them upgrades to their weapons for virtually fighting cancer.

The fourth aim identified is symptom management. The game mechanic of role modelling can also be used here. In Pain Buddy, the animal avatar helps to demonstrate pain management techniques to the users via speech and animation. Users can then practice these techniques by mimicking what they see on the screen. This aim is also linked to the aim of encouraging healthy habits. There is an overlap as taking care of one's health will also help reduce the severity of many cancer symptoms. The game mechanic of symptom or health reporting also aids in achieving this aim. Cancer patients will be able to report or log the state of their symptoms and its severity to the game or application. This information can then be sent to a server where trends can be studied. 
This leads to the fifth game aim of communication with health care providers. This game aim is seen to be paired with the game mechanic of symptom reporting in Pain Buddy and INTERACCT. The data collected on the servers can be viewed by the health care providers who can then show better support to the cancer patients as a result of being updated on a daily basis regarding the patients' symptom and health statuses. In INTERACCT, the health care providers are not only able to view this information, they are also able to use the mini-game mechanic to assign medical-purposed mini games to the players to help them cope with the symptoms and encourage good health habits, for example to increase fluid intake if the players have reported a lower intake of fluids.

Last but not least is the game aim for improving treatment adherence. The game mechanic of fighting enemies with cancer treatment depicted as weapons for fighting cancer cells will help players to see how these treatments work. As seen in the evaluation of Re-Mission, this raises their belief in cancer treatment as an efficient way to fight cancer, and as a result, the cancer patients started to adhere more to their chemotherapy drug regime. The alarm system game mechanic used in ILOVEBREAST to remind players to help their avatars to take their medications on time. Additionally, the quest/challenges mechanic is also used in the same game to ask the avatar to take their medications in a timely manner. This action is further encouraged through the game mechanic of virtual rewards, as with the completion of the medication taking quest, players are awarded with heart coins which boosts the avatar's health and can be spent to buy items in the game.

The game mechanics used for each intervention, and the total number of interventions that utilize the game mechanic are shown in and Table 3.

Table 3. Game mechanics found in each DHI.

\begin{tabular}{|c|c|c|c|c|c|c|c|c|c|c|c|c|}
\hline $\begin{array}{c}\text { Game } \\
\text { mechanic } \\
\text { code }\end{array}$ & 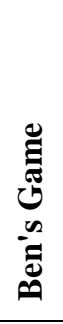 & 号 & 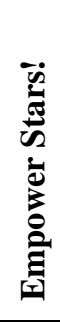 & 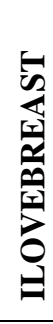 & 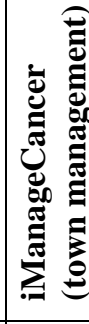 & 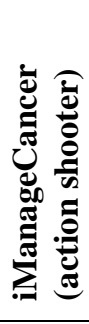 & 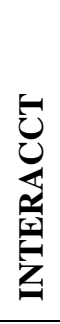 & 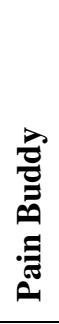 & 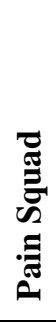 & 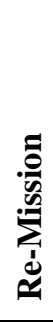 & 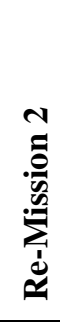 & $\stackrel{5}{0}$ \\
\hline Virtual rewards & 1 & & 1 & 1 & 1 & 1 & 1 & 1 & 1 & & & 8 \\
\hline $\begin{array}{l}\text { Fighting } \\
\text { enemies }\end{array}$ & 1 & 1 & 1 & & & 1 & 1 & & & 1 & 1 & 7 \\
\hline Custom avatar & & & & 1 & 1 & & 1 & 1 & & & & 4 \\
\hline Role-modelling & & & & 1 & 1 & & & 1 & & 1 & & 4 \\
\hline Mini-game & & & 1 & & 1 & & 1 & & & & & 3 \\
\hline $\begin{array}{l}\text { Symptom/health } \\
\text { reporting }\end{array}$ & & & & & & & 1 & 1 & 1 & & & 3 \\
\hline $\begin{array}{l}\text { Quests/ } \\
\text { Challenges }\end{array}$ & & & & 1 & 1 & & & & & & & 2 \\
\hline Social & & & & & 1 & 1 & & & & & & 2 \\
\hline $\begin{array}{l}\text { Detect physical } \\
\text { movement }\end{array}$ & & & 1 & & & & & & & & & 1 \\
\hline Alarm system & & & & 1 & & & & & & & & 1 \\
\hline Unlockables & & & & & & & 1 & & & & & 1 \\
\hline $\begin{array}{l}\text { Randomly } \\
\text { generated levels }\end{array}$ & & & & & & & 1 & & & & & 1 \\
\hline
\end{tabular}


Game mechanics that are for achieving game aims in the 11 DHIs described are: fighting enemies (7), role-modelling (4), mini-game (3), symptom/health reporting (3), quests/challenges (2), social (2), detect physical movement (1), and alarm system (1).

These game mechanics contribute directly to the aim of the game. For example, fighting enemies is linked to empowerment of cancer patients to fight cancer. Rolemodelling shows the effects of certain behaviors on the avatar's or game character's wellbeing, allowing the players to experience these scenarios through the game. Therefore, this game mechanic can help to encourage healthy habits, and educate players about cancer. Mini-games are used for achieving additional aims such as educating players about cancer and related information. Symptom and health reporting mechanics contribute directly to the symptom management aim as it allows the players to report their symptom status. Quest and challenges can provide players with goals for the game and can include the practice of good health habits. Social game mechanics allow players to socialize and feel involved with others, and contributes the encouragement of the good habit of socializing with other people. The game mechanic of detecting physical movement is a primary requirement of exergames as it detects if players are physically moving. This helps to encourage the good habit of exercising. Finally, the alarm system is used to encourage treatment adherence, as it is able to provide reminders.

On the other hand, some game mechanics are for encouraging game play: virtual rewards (8), custom avatar (4), quest/challenges (2), unlockables (1), and randomly generated levels (1). These can be used to encourage engagement and participation by players. These mechanics can also motivate players to come back to the game or application, and provide additional incentive to make progress.

Table 4. Platform and target cancer patient group of each DHI.

\begin{tabular}{|c|c|c|c|c|c|c|c|c|c|c|c|c|}
\hline $\begin{array}{l}\text { Platform and } \\
\text { target cancer } \\
\text { patient group }\end{array}$ & 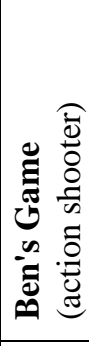 & 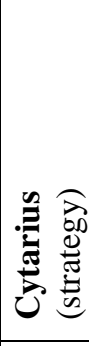 & 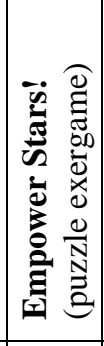 & 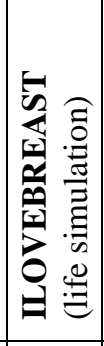 & 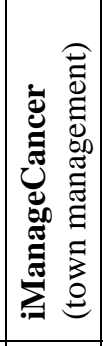 & 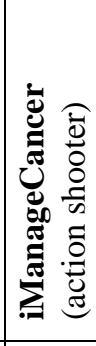 & 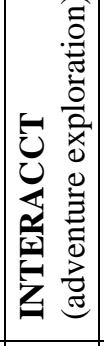 & 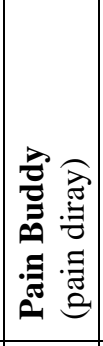 & 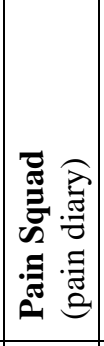 & 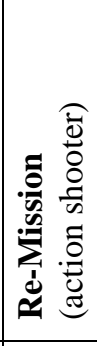 & 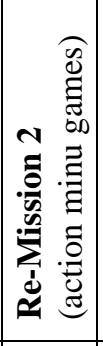 & 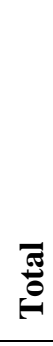 \\
\hline $\begin{array}{l}\text { Computer } \\
\text { platform }\end{array}$ & 1 & 1 & & & & & & & & 1 & 1 & 4 \\
\hline Mobile platform & & & 1 & 1 & 1 & 1 & 1 & 1 & 1 & & 1 & 8 \\
\hline Targets adults & & & & 1 & 1 & & & & & 1 & 1 & 4 \\
\hline $\begin{array}{l}\text { Targets children } \\
\text { and adolescents }\end{array}$ & 1 & 1 & 1 & & & 1 & 1 & 1 & 1 & 1 & 1 & 9 \\
\hline
\end{tabular}

Game-based DHIs show that interventions can be delivered not only in an interactive way, but that patients can also have fun while going through it. According to Table 4, the mobile platform is the main choice of many interventions ( $72 \%$ of the interventions reviewed) due to its portability, which allows the patients to play the game at any time and place. Additionally, many of these interventions target children and or adolescents with cancer $(82 \%)$. Among the seven different games for children with cancer, many of the games targeted towards children involve fighting enemies, and are of the action or adventure type game genre. Being able to fight enemies is in line with the primary game aim of many interventions to empower their players to fight cancer. Other game genres involved more thinking such as strategy and puzzle games. On the other hand, games targeted towards only adults patients involved more problem solving, and are the life simulation game, and the town management game. 


\section{Limitations and future work}

This section discusses the limitations of this review, the limitations of existing work, and provides recommendations for future work.

\subsection{Limitations}

Articles found for this review were limited to articles on available database access, open access articles, and web articles.

In addition, the analysis of each intervention is scoped to the following factors: platform the intervention is on, game genre or type of intervention, target user or player group, game aims, and game mechanics. A brief description of the intervention results is also given provided that the intervention trial results have been published.

\subsection{Limitations of existing work}

The findings of this review show the limitations of existing game-based DHIs. The game aim of treatment adherence was only addressed in 3 out of 11 interventions reviewed. Although the game aim of empowerment to fight cancer can improve treatment adherence, most interventions did not conduct tests for this aspect, therefore the effects on treatment adherence for those studies could not be verified.

Additionally, although cancer and cancer treatment can result in a large range of symptoms, both interventions (Pain Buddy and Pain Squad) that have symptom management as their main aim, focused only on the symptom of pain. While Re-Mission did address more of these symptoms by allowing the players to fire related items at a symptom when it occurs, such as stool softeners for constipation, there was no additional content on symptom management beyond this action.

Lastly, despite the potential benefits of collaborating with health care providers to improve the care of young cancer patients through a game-based intervention, the game aim of communication with health care providers was only included in 2 out of 11 of the interventions analyzed.

Although this review shows that digital health interventions can achieve various game aims through the use of game mechanics, there are still limitations that need to be addressed to improve how these interventions are able to help children with cancer.

\subsection{Future work}

Based on the findings and limitations discussed, it is recommended that future digital health interventions targeting young cancer patients place more importance on the game aims of treatment adherence and empowerment to fight cancer, given that cancer treatment adherence is of absolute importance in surviving childhood cancer. The game mechanics of fighting enemies and role-modelling can help achieve these game aims.

In addition, for future interventions that aim to help patients to manage their symptoms, more focus should be placed on a larger number of symptoms as cancer patients often experience a range of symptoms during the cancer treatment period. The game mechanic of role-modelling should be used in such interventions to demonstrate the management techniques of other common symptoms such as mucositis, nausea, fatigue, and sleep disturbances.

Future interventions should also aim to collaborate with health care providers whenever feasible. Involving the health care providers of young cancer patients in the monitoring and management of their health, especially while the patients are away from the hospital will ensure better care and advice is being provided. The game mechanic that can aid with the collaboration with health care providers is the symptom/health reporting game mechanic. Reports generated from this game mechanic can give health care 
pag. 86

providers a better understanding of the patient's health, thus allowing them to provide better care for the patient and give more accurate health advice.

Furthermore, future interventions should include game mechanics that are designed to encourage continuous game play such as virtual rewards, custom avatars, quests and challenges, unlockables and randomly generated levels.

Lastly, As DHIs are easily scalable, future interventions should strive to include multiple game aims supported by well-designed game mechanics to ensure better overall care for young cancer patients.

\section{Conclusion}

Game-based DHIs have been used to aid young cancer patients to make the cancer experience more bearable. The review conducted on 11 of these interventions has identified the multiple game aims, and various game mechanics used to support the objectives of these DHIs.

Game aims identified include empowerment to fight cancer, education on cancer, encourage healthy habits, and symptom management, treatment adherence, and communication with health care providers. These game aims are supported through the use of game mechanics such as fighting enemies, role-modelling, mini-games, symptom/health reporting, social, detect physical movement, and alarm system. Game aims and game mechanics are interlinked and the relationship between how these game aims are supported by the various game mechanics have been discussed in this article.

It has also been identified that many interventions have included incentives to encourage players to keep playing the game. Incentives are added to the interventions through the implementation of game mechanics such as virtual rewards, custom avatar, quests/challenges, unlockables, and randomly generated levels.

Therefore, it is shown that an engaging and effective game-based DHI for young cancer patients should contain clear game aims to address the various difficulties faced by the young players. It should also include the relevant game mechanics to support these aims, and to boost players' engagement. .

\section{References}

[1] K. Pritchard-Jones et al., "Sustaining innovation and improvement in the treatment of childhood cancer: Lessons from high-income countries," Lancet Oncol., vol. 14, no. 3, pp. e95-e103, 2013. doi:10.1016/S1470-2045(13)70010-X

[2] J. Ferlay et al., "Cancer incidence and mortality worldwide: Sources, methods and major patterns in GLOBOCAN 2012," Int. J. Cancer, vol. 136, no. 5, pp. E359-E386, Mar. 2015. doi:10.1002/ijc.29210

[3] L. McCann, Kathryn Anne McMillan, and Gemma Pugh, "Digital interventions to support adolescents and young adults with cancer: Systematic review," Journal of Medical Internet Research, vol. 21, no. 7. Journal of Medical Internet Research, 2019.

[4] M. Ghazisaeidi, R. Safdari, A. Goodini, M. Mirzaiee, and J. Farzi, "Digital games as an effective approach for cancer management: Opportunities and challenges," J. Educ. Health Promot., vol. 6, no. 1, p. 30, May 2017. doi:10.4103/jehp.jehp_146_14

[5] R. McCulloch, J. Hemsley, and P. Kelly, "Symptom management during chemotherapy," Paediatr. Child Heal. (United Kingdom), vol. 28, no. 4, pp. 189-195, 2018. doi:10.1016/j.paed.2018.02.003

[6] P. W. Alcoser and C. Rodgers, "Treatment strategies in childhood cancer," J. Pediatr. Nurs., vol. 18, no. 2, pp. 103-112, 2003. doi:10.1053/jpdn.2003.10

[7] U. Pöder, G. Ljungman, and L. Von Essen, "Parents' perceptions of their children's cancer-related symptoms during treatment: A prospective, longitudinal study," J. Pain Symptom Manage., vol. 40, no. 5, pp. 661-670, Nov. 2010. doi:10.1016/j.jpainsymman.2010.02.012

[8] L. Hedén, U. Pöder, L. Von Essen, and G. Ljungman, "Parents' perceptions of their child's symptom burden during and after cancer treatment," J. Pain Symptom Manage., vol. 46, no. 3, pp. 366-375, 2013. doi:10.1016/j.jpainsymman.2012.09.012

[9] N. Altay, E. Kilicarslan-Toruner, and Ç. Sari, "The effect of drawing and writing technique on the anxiety level of children undergoing cancer treatment," Eur. J. Oncol. Nurs., vol. 28, pp. 1-6, 2017. doi:10.1016/j.ejon.2017.02.007 
[10] L. Korsvold, A. V. Mellblom, A. Finset, E. Ruud, and H. C. Lie, "A content analysis of emotional concerns expressed at the time of receiving a cancer diagnosis: An observational study of consultations with adolescent and young adult patients and their family members," Eur. J. Oncol. Nurs., vol. 26, pp. 1-8, 2017. doi:10.1016/j.ejon.2016.10.005

[11] I. Odh, M. Löfving, and K. Klaeson, "Existential challenges in young people living with a cancer diagnosis," Eur. J. Oncol. Nurs., vol. 24, pp. 54-60, 2016. doi:10.1016/j.ejon.2016.08.005

[12] B. Kim, K. White, and P. Patterson, "Understanding the experiences of adolescents and young adults with cancer: A meta-synthesis," Eur. J. Oncol. Nurs., vol. 24, pp. 39-53, 2016. doi:10.1016/j.ejon.2016.06.002

[14] H. J. Kondryn, C. L. Edmondson, J. Hill, and T. O. B. Eden, "Treatment non-adherence in teenage and young adult patients with cancer," Lancet Oncol., vol. 12, no. 1, pp. 100-108, 2011. doi:10.1016/S14702045(10)70069-3

[15] L. Miauton, F. Narring, and P. A. Michaud, "Chronic illness, life style and emotional health in adolescence: Results of a cross-sectional survey on the health of 15-20-year-olds in Switzerland," Eur. J. Pediatr., vol. 162, no. 10, pp. 682-689, Oct. 2003. doi:10.1007/s00431-003-1179-x

[16] M. Webster, "Similarities and differences in the meanings children and their parents attach to epilepsy medications," Soc. Sci. Med., vol. 177, pp. 190-197, 2017. doi:10.1016/j.socscimed.2017.01.065

[17] P. Kardas, P. Lewek, and M. Matyjaszczyk, "Determinants of patient adherence: A review of systematic reviews," Front. Pharmacol., vol. 4, 2013. doi:10.3389/fphar.2013.00091

[18] S. N. A. Ghani, H. A. Ainuddin, and A. Dahlan, "Quality of Life Amongst Family Caregivers of Older Persons with Terminal Illnesses," Procedia - Soc. Behav. Sci., vol. 234, pp. 135-143, 2016. doi:10.1016/j.sbspro.2016.10.228

[19] H. C. W. Li, V. Lopez, O. K. Joyce Chung, K. Y. Ho, and S. Y. Chiu, "The impact of cancer on the physical, psychological and social well-being of childhood cancer survivors," Eur. J. Oncol. Nurs., vol. 17, no. 2, pp. 214-219, 2013. doi:10.1016/j.ejon.2012.07.010

[20] E. R. Zamora, J. Yi, J. Akter, J. Kim, E. L. Warner, and A. C. Kirchhoff, “'Having cancer was awful but also something good came out': Post-traumatic growth among adult survivors of pediatric and adolescent cancer,” Eur. J. Oncol. Nurs., vol. 28, pp. 21-27, 2017. doi:10.1016/j.ejon.2017.02.001

[21] M. Tremolada, S. Bonichini, G. Basso, and M. Pillon, "Adolescent and young adult cancer survivors narrate their stories: Predictive model of their personal growth and their follow-up acceptance," Eur. $J$. Oncol. Nurs., vol. 36, pp. 119-128, 2018. doi:10.1016/j.ejon.2018.09.001

[22] C. L. David, K. Williamson, and D. W. O. Tilsley, "A small scale, qualitative focus group to investigate the psychosocial support needs of teenage young adult cancer patients undergoing radiotherapy in Wales," Eur. J. Oncol. Nurs., vol. 16, no. 4, pp. 375-379, 2012. doi:10.1016/j.ejon.2011.08.002

[23] J. K. Jones, S. A. Kamani, P. J. Bush, K. A. Hennessy, A. Marfatia, and A. T. Shad, "Development and evaluation of an educational interactive CD-ROM for teens with cancer," Pediatr. Blood Cancer, vol. 55, no. 3, pp. 512-519, Sep. 2010. doi:10.1002/pbc.22608

[24] P. C. Trask, A. G. Paterson, C. L. Trask, C. B. Bares, J. A. Birt, and C. Maan, "Parent and adolescent adjustment to pediatric cancer: Associations with coping, social support, and family function," $J$. Pediatr. Oncol. Nurs., vol. 20, no. 1, pp. 36-47, 2003. doi:10.1053/jpon.2003.5

[25] R. J. Paxton, L. W. Jones, P. M. Rosoff, M. Bonner, J. L. Ater, and W. Demark-Wahnefried, "Associations between leisure-time physical activity and health-related quality of life among adolescent and adult survivors of childhood cancers," Psychooncology., vol. 19, no. 9, pp. 997-1003, Sep. 2010. doi:10.1002/pon.1654

[26] N. Gariépy and N. Howe, "The therapeutic power of play: Examining the play of young children with leukaemia," Child. Care. Health Dev., vol. 29, no. 6, pp. 523-537, Nov. 2003. doi:10.1046/j.13652214.2003.00372.x

[27] S. L. Nijhof et al., "Healthy play, better coping: The importance of play for the development of children in health and disease," Neurosci. Biobehav. Rev., vol. 95, no. July, pp. 421-429, 2018. doi:10.1016/j.neubiorev.2018.09.024

[28] A. Sala et al., "Nutritional status at diagnosis is related to clinical outcomes in children and adolescents with cancer: A perspective from Central America," Eur. J. Cancer, vol. 48, no. 2, pp. 243-252, Jan. 2012. doi:10.1016/j.ejca.2011.06.006

[29] P. A. Wilkes and D. H. Allen, "Nutrition Care: Managing Symptoms From Cancer," J. Nurse Pract., vol. 14, no. 4, pp. 267-275.e3, 2018. doi:10.1016/j.nurpra.2018.01.011

[30] J. A. Virizuela et al., "Nutritional support and parenteral nutrition in cancer patients: an expert consensus report," Clin. Transl. Oncol., vol. 20, no. 5, pp. 619-629, May 2018. doi:10.1007/s12094$017-1757-4$

[31] American Cancer Society, "Preventing Infections in People With Cancer," 2015. [Online]. Available: https://www.cancer.org/treatment/treatments-and-side-effects/physical-sideeffects/infections/preventing-infections-in-people-with-cancer.html. [Accessed: 23-Jul-2019].

[32] C. R. Phillips and L. L. Davis, "Psychosocial Interventions for Adolescents and Young Adults with Cancer," Semin. Oncol. Nurs., vol. 31, no. 3, pp. 242-250, 2015. doi:10.1016/j.soncn.2015.05.004

[33] A. Coughtrey et al., "The Effectiveness of Psychosocial Interventions for Psychological Outcomes in Pediatric Oncology: A Systematic Review," J. Pain Symptom Manage., vol. 55, no. 3, pp. 1004-1017, 2018. doi:10.1016/j.jpainsymman.2017.09.022

[34] W. H. C. Li et al., "Adventure-based training to promote physical activity and reduce fatigue among 
childhood cancer survivors: A randomized controlled trial," Int. J. Nurs. Stud., vol. 83, pp. 65-74, 2018. doi:10.1016/j.ijnurstu.2018.04.007

[35] D. Mizrahi et al., "Distance-delivered physical activity interventions for childhood cancer survivors: A systematic review and meta-analysis," Crit. Rev. Oncol. Hematol., vol. 118, pp. 27-41, 2017. doi:10.1016/j.critrevonc.2017.08.008

[36] K. K. W. Lam et al., "An integrated experiential training programme with coaching to promote physical activity, and reduce fatigue among children with cancer: A randomised controlled trial," Patient Educ. Couns., vol. 101, no. 11, pp. 1947-1956, 2018. doi:10.1016/j.pec.2018.07.008

[37] H. L. Su, L. M. Wu, S. S. Chiou, P. C. Lin, and Y. M. Liao, "Assessment of the effects of walking as an exercise intervention for children and adolescents with cancer: A feasibility study," Eur. J. Oncol. Nurs., vol. 37, pp. 29-34, 2018. doi:10.1016/j.ejon.2018.10.006

[38] E. Murray et al., "Evaluating Digital Health Interventions: Key Questions and Approaches," American Journal of Preventive Medicine, vol. 51, no. 5. Elsevier Inc., pp. 843-851, 01-Nov-2016. doi:10.1016/j.amepre.2016.06.008

[39] A. Stålberg, A. Sandberg, M. Söderbäck, and T. Larsson, "The child's perspective as a guiding principle: Young children as co-designers in the design of an interactive application meant to facilitate participation in healthcare situations," J. Biomed. Inform., vol. 61, pp. 149-158, 2016. doi:10.1016/j.jbi.2016.03.024

[40] Make-A-Wish Foundation of America, "Ben's Video Game Fights Cancer," 2012. [Online]. Available: http://wish.org/wishes/wish-stories/i-wish-to-be/ben-video-game-creator. [Accessed: 21-Oct-2018].

[41] A. J. Voortman, "Serious Games: Learning skills by means of computer games," Vrije Universiteit Amsterdam, 2011.

[42] J. Ball, "Boy inspires cancer video game," 2004. [Online]. Available: http://news.bbc.co.uk/2/hi/technology/3839091.stm. [Accessed: 12-Feb-2020].

[43] K. Gerling, A. Fuchslocher, R. Schmidt, N. Krämer, and M. Masuch, "Designing and evaluating casual health games for children and teenagers with cancer," Lect. Notes Comput. Sci. (including Subser. Lect. Notes Artif. Intell. Lect. Notes Bioinformatics), vol. 6972 LNCS, pp. 198-209, 2011. doi:10.1007/978-3642-24500-8_21

[44] C. S. Bruggers et al., "A Prototype Exercise-Empowerment Mobile Video Game for Children With Cancer, and Its Usability Assessment: Developing Digital Empowerment Interventions for Pediatric Diseases," Front. Pediatr., vol. 6, Apr. 2018. doi:10.3389/fped.2018.00069

[45] Dictionary.com, "Exergaming," [Online]. $2020 . \quad$ Available: https://www.dictionary.com/browse/exergaming. [Accessed: 12-Feb-2020].

[46] H. J. Kim, S. M. Kim, H. Shin, J. S. Jang, Y. I. Kim, and D. H. Han, "A mobile game for patients with breast cancer for chemotherapy self-management and quality-of-life improvement: Randomized controlled trial," J. Med. Internet Res., vol. 20, no. 10, p. e273, 2018. doi:10.2196/jmir.9559

[47] IManageCancer, "iManageCancer," 2018. [Online]. Available: http://imanagecancer.eu/. [Accessed: 23 Jul-2019].

[48] S. Hoffmann and S. Wilson, "The role of serious games in the iManageCancer project," Ecancermedicalscience, vol. 12, Jul. 2018. doi:10.3332/ecancer.2018.850

[49] H. Kondylakis et al., "Patient empowerment for cancer patients through a novel ICT infrastructure," $J$. Biomed. Inform., vol. 101, no. November 2018, p. 103342, 2020. doi:10.1016/j.jbi.2019.103342

[50] F. Kayali et al., "Design considerations for a serious game for children after hematopoietic stem cell transplantation," Entertain. Comput., vol. 15, pp. 57-73, 2016. doi:10.1016/j.entcom.2016.04.002

[51] K. Peters et al., "Serious Game Scores as Health Condition Indicator for Cancer Patients," Stud. Health Technol. Inform., vol. 210, pp. 892-896, 2015.

[52] M. A. Fortier, W. W. Chung, A. Martinez, S. Gago-Masague, and L. Sender, "Pain buddy: A novel use of m-health in the management of children's cancer pain," Comput. Biol. Med., vol. 76, pp. 202-214, 2016. doi:10.1016/j.compbiomed.2016.07.012

[53] J. N. Stinson et al., "Development and testing of a multidimensional iphone pain assessment application for adolescents with cancer," J. Med. Internet Res., vol. 15, no. 3, p. e51, 2013. doi:10.2196/jmir.2350

[54] HopeLab, "Re-Mission," 2018. [Online]. Available: http://www.re-mission.net. [Accessed: 21-Oct2018].

[55] HopeLab, "Re-Mission 2: Fight cancer and WIN! Games for cancer support based on scientific research,” 2018. [Online]. Available: http://www.re-mission2.org. [Accessed: 21-Oct-2018].

[56] Roswell Park Comprehensive Cancer Center, "Zapping Cancer Through Video Games,” 2013. [Online]. Available: https://www.roswellpark.org/cancertalk/201307/zapping-cancer-through-video-games. [Accessed: 21-Oct-2018].

[57] Business Wire, "New Cancer-Fighting Game App Goes Global," 2013. [Online]. Available: https://www.businesswire.com/news/home/20130819005809/en/New-Cancer-Fighting-Game-AppGlobal. [Accessed: 21-Oct-2018].

[58] A. Bandura and R. H. Walters, Social learning theory. Englewood Cliffs, NJ: Prentice-hall, 1977. 